\title{
A comparison of diagnostic tests for lactose malabsorption - which one is the best? Øistein Hovde ${ }^{1}$ and Per G Farup*1,2
} Address: ${ }^{1}$ Department of Medicine, Innlandet Hospital Trust, Gjøvik, Norway and ${ }^{2}$ Unit for Applied Clinical Research, Norwegian University of
Science and Technology, Trondheim, Norway

Email: Øistein Hovde - oistein.hovde@sykehuset-innlandet.no; Per G Farup* - per.farup@ntnu.no

* Corresponding author

Published: 31 October 2009

BMC Gastroenterology 2009, 9:82 doi:10.1 186/147|-230X-9-82

This article is available from: http://www.biomedcentral.com/I47I-230X/9/82

(c) 2009 Hovde and Farup; licensee BioMed Central Ltd.

This is an Open Access article distributed under the terms of the Creative Commons Attribution License (http://creativecommons.org/licenses/by/2.0), which permits unrestricted use, distribution, and reproduction in any medium, provided the original work is properly cited.
Received: 27 June 2009

Accepted: 31 October 2009

\begin{abstract}
Background: Perceived milk intolerance is a common complaint, and tests for lactose malabsorption (LM) are unreliable. This study assesses the agreement between diagnostic tests for LM and describes the diagnostic properties of the tests.

Methods: Patients above 18 years of age with suspected LM were included. After oral intake of $25 \mathrm{~g}$ lactose, a combined test with measurement of serum glucose (s-glucose) and hydrogen $(\mathrm{H} 2)$ and methane $(\mathrm{CH} 4)$ in expired air was performed and symptoms were recorded. In patients with discrepancies between the results, the combined test was repeated and a gene test for lactose nonpersistence was added. The diagnosis of $L M$ was based on an evaluation of all tests. The following tests were compared: Increase in $\mathrm{H} 2, \mathrm{CH} 4, \mathrm{H} 2+\mathrm{CH} 4$ and $\mathrm{H} 2+\mathrm{CH} 4 \times 2$ in expired air, increase in sglucose, and symptoms. The agreement was calculated and the diagnostic properties described.
\end{abstract}

Results: Sixty patients were included, seven (I $\%$ ) had LM. The agreement (kappa-values) between the methods varied from 0.25 to 0.91 . The best test was the lactose breath test with measurement of the increase in $\mathrm{H} 2+\mathrm{CH} 4 \times 2$ in expired air. With a cut-off level $<18 \mathrm{ppm}$, the area under the ROC-curve was 0.967 and sensitivity was $100 \%$. This shows that measurement of $\mathrm{CH} 4$ in addition to $\mathrm{H} 2$ improves the diagnostic properties of the breath test.

Conclusion: The agreement between commonly used methods for the diagnosis of LM was unsatisfactory. A lactose breath test with measurement of $\mathrm{H} 2+\mathrm{CH} 4 \times 2$ in expired air had the best diagnostic properties.

\section{Background}

The population based prevalence of lactose malabsorption (LM) in Scandinavia is 2-8\% [1-3]. The prevalence of LM is in the same order in subjects with functional gastrointestinal disorders (FGID) as in the general population, whereas perceived milk and lactose intolerance is reported by $30-67 \%$ of subjects with FGID [2,4-7]. Dietary advice to subjects with FGID and to those with intolerance to milk and lactose relies on a valid and reliable diagnostic test for LM. Such a test is not available.

Lactose is an unabsorbable disaccharide hydrolysed by lactase (lactase-phlorizin hydrolase) in the intestinal brush border into galactose and glucose that are absorbed. LM is a failure to hydrolyse lactose. In adults the most common cause is a genetic defect with lack of intestinal 
lactase. The unabsorbed lactose is metabolised by colonic bacteria to produce gas (hydrogen $(\mathrm{H} 2)$ and methane (CH4)) and short chain fatty acids. Clinical manifestations of LM are abdominal pain/discomfort, borborygmi, bloating, flatulence and diarrhoea $[2,8]$. In subjects with LM, symptoms depend on the amount of lactose. Most people with LM can, due to colonic adaptation to regular lactose ingestion, ingest up to 6-12 g lactose (120 - 240 mL milk) without developing symptoms [9-11].

Commonly used tests for the diagnosis of LM are based on an exaggerated increase in $\mathrm{H} 2$ and/or $\mathrm{CH} 4$ in the expired air after intake of lactose, or an inappropriate increase in serum glucose (s-glucose). Other tests are assessment of lactase activity in jejunal biopsies, a test for genetic defects $[12,13]$, and registration of symptoms after intake of lactose [14]. Recently, the Rome Consensus Conference published a review of the methodology and indications of $\mathrm{H2}$ breath testing in gastrointestinal diseases [15]. No "gold standard" is available for the diagnosis of LM and breath tests with measurement of volatile compounds and other gases (mainly $\mathrm{CH} 4$ ) were encouraged [15]. There are few comparisons between the tests and no agreement upon which one is the best.

The aims of this study were to assess the agreement between commonly used diagnostic methods for LM (breath test, s-glucose and symptoms), describe the diagnostic properties of the methods and establish the best method and cut-off levels for clinical use.

\section{Methods \\ Subjects}

Patients with intolerance to milk or dairy products and/or unexplained abdominal discomfort consistent with LM seen in one outpatient gastroenterological unit were invited to participate in the study. Exclusion criteria were age below 18 years, insufficient understanding of written instructions, intake of antibiotics the last two weeks and a previous diagnosis of LM. Age, sex, Body Mass Index (BMI), ethnicity, smoking habits, the patients' reaction to milk and dairy products, and current and past diseases were noted.

\section{Methods}

The initial diagnostic test for LM was a combined breathand s-glucose test after intake of $25 \mathrm{~g}$ lactose. The test was performed at the hospital in the morning. Prior to the test the patients were on a low fibre diet for 48 hours, and they were not allowed to eat, drink or smoke the last 12 hours before the test. Physical activity, except for the limited activity necessary to reach the hospital, was prohibited in the morning before the test. $\mathrm{H} 2$ and $\mathrm{CH} 4$ were measured in the expiratory air before, and 30, 60, 120, and $180 \mathrm{~min}-$ utes after intake of lactose with a stationary gas chromato- graph (SC MicroLyzer, QuinTron Instrument Co, Milwaukee, Wisc., USA). Alveolar air was collected using a Y-piece device (QuinTron AlveoSampler) after $10 \mathrm{sec}-$ onds' expiration, analysed immediately after the collection and corrected for alveolar CO2. Samples for s-glucose were taken before, and 15, 30, 60, and 90 minutes after intake of lactose. An increase in $\mathrm{H} 2 \geq 20 \mathrm{ppm}$ (parts per million) compared to the lowest measured value, an increase in $\mathrm{CH} 4 \geq 12 \mathrm{ppm}$ compared to the value measured before the intake of lactose, or an increase in the sum of $\mathrm{H} 2$ and $\mathrm{CH} 4 \geq 15 \mathrm{ppm}$ was considered as a diagnostic test for LM, as was increase in s-glucose $<1.1 \mathrm{mmol} / \mathrm{L}$ from baseline. If the s-glucose test and the breath test had concurrent outcomes (both were normal or abnormal), the patient was classified as not having LM or having LM.

Twenty-four hours after the first combined breath- and sglucose tests the patients filled in a questionnaire which was returned to the hospital. They were asked about the presence of abdominal symptoms during and for 24 hours after the combined test. If abdominal symptoms were present, they answered three additional questions: 1 ) When did the symptoms start? (during the test or $0-2 \mathrm{~h}, 2-$ $4 \mathrm{~h}, 4-8 \mathrm{~h},>8 \mathrm{~h}$ after the test) 2) What type of symptoms have you experienced? (abdominal pain/discomfort, borborygmi, bloating, diarrhoea, or constipation) and 3 ) How long did the symptoms last? $(0-2$ h, 2-4 h, 4-8 h, $>8$ h). In accordance with a previous study, symptoms starting within $5 \mathrm{~h}$ after intake of lactose and lasting for more than $2 \mathrm{~h}$ were classified as "Early and Long Lasting" (ELL) [2].

In cases of discrepancies between the initial breath test and the s-glucose test, the combined test was repeated without registration of symptoms, and a diagnostic gene test (Lactase C-13910T, chromosome 2q21-22) was added $[12,13]$. The gene tests were analyzed at the Hormone Laboratory, Aker University Hospital, Oslo, Norway. In patients with discrepancies between the breathand the s-glucose test at the first combined test, a total of five tests were available: Two sets of breath tests, two sets of s-glucose tests and one gene test. The presumed correct diagnosis was based on an evaluation of all tests. If three or more tests were abnormal, it was concluded that the patient had LM.

Because the synthesis of $\mathrm{CH} 4$ consumes large amounts of $\mathrm{H} 2$, an increase in $\mathrm{CH} 4$ in the expiratory air reduces the production of $\mathrm{H} 2$. Therefore, the diagnostic properties of the increase in $\mathrm{H} 2+\mathrm{CH} 4 \times 2$ were studied in addition to the conventional variables $(\mathrm{H} 2, \mathrm{CH} 4, \mathrm{H} 2+\mathrm{CH} 4$, s-glucose and symptoms). The diagnostic properties of the gene test are not reported because of the limited number of analyses. The results of all tests (the first and the repeated ones) 
were used for evaluation of the diagnostic properties of the test variables.

In search of optimal cut-off levels for screening purposes, high sensitivity and therefore a lower specificity, was preferred, with further diagnostic examinations in subjects with positive tests.

\section{Statistical analyses}

Comparisons between the groups were analysed with Mann-Whitney test and Fisher's exact test, and agreement with kappa statistics. Receiver Operating Characteristic (ROC) curves describe the diagnostic properties of the variables. SPSS version 14.0 with exact tests was used for the analyses. P-values $<0.05$ were considered statistically significant, and 95\% confidence intervals (CI) were calculated for the main variables.

\section{Ethics}

The study was conducted according to the Declaration of Helsinki, and approved by the Regional Committee for Medical Research Ethics, Trondheim, Norway and Norwegian Social Science Data Services. Written informed consent was given by all participants before inclusion.

\section{Results}

Sixty patients were included. Five patients had LM and 45 had not after the first combined breath- and s-glucose test (both tests were clearly positive or negative). In ten patients with discrepancies between the blood- and breath tests, the combined test was repeated and the gene test performed. Two of these ten patients were classified as having LM (they had three positive and two negative tests) and eight were normal (four patients had two positive and three negative tests, and four patients had one positive and four negative tests). The gene test was positive in one of the two patients with LM, and negative in eight patients without LM. In total, seven patients $(12 \%)$ were classified as having $\mathrm{LM}$.

Table 1 gives the characteristics of patients with and without LM. Except for a lower BMI in patients with LM, there were no significant differences between the groups. Four patients had organic diseases in clinical remission (three had ulcerative colitis and one Crohn's disease), none of them had LM. Fifty-six patients had functional bowel disorders. In patients with and without $\mathrm{LM}$ the increase in $\mathrm{H} 2$ (mean and range) were $59 \mathrm{ppm}(0-170)$ and $5 \mathrm{ppm}(0-$ 52) respectively, increase in $\mathrm{CH} 4$ were $3 \mathrm{ppm}(0-13)$ and 1 ppm (0-20) respectively, increase in $\mathrm{H} 2+\mathrm{CH} 4$ were 62 ppm (13-170) and 6 ppm (0-52) respectively, increase in $\mathrm{H} 2+\mathrm{CH} 4 \mathrm{x} 2$ were $65 \mathrm{ppm}(18-170)$ and $7 \mathrm{ppm}(0-52)$ respectively, and increase in blood glucose were 0.7 $\mathrm{mmol} / \mathrm{L} \mathrm{(0.1-1.5)} \mathrm{and} 2.0 \mathrm{mmol} / \mathrm{L}(0.7-4.6)$ respectively.

One patient did not fill in the symptom questionnaire after the lactose test, and one patient did not report exact indication of time, which made evaluation of ELL impossible. Table 2 gives the symptoms in the groups with and without LM. Presence of any ELL symptom had the best diagnostic properties, and pain/discomfort-ELL, borborygmi-ELL, and bloating-ELL were all statistically significantly related to LM.

Table 3 gives the results of the receiver operating characteristics curves (ROC) analyses. The breath test with measurement of $\mathrm{H} 2+\mathrm{CH} 4 \times 2$ was the best one. The best cut-off levels (normal values) for the increase in $\mathrm{H} 2+\mathrm{CH} 4 \times 2$, $\mathrm{H} 2+\mathrm{CH} 4, \mathrm{H} 2$, and s-glucose were considered to be $<18$ ppm, $<17 \mathrm{ppm},<16 \mathrm{ppm}$, and $>0.9 \mathrm{mmol} / \mathrm{L}$ respectively. Table 4 gives the agreement between the test variables with these cut-off levels. With this cut-off level, the sensitivity of $\mathrm{H} 2+\mathrm{CH} 4 \times 2$ was $100 \%$.

Table 5 gives the sensitivity, specificity, positive and negative predictive values, accuracy and likelihood ratio (LR+ and LR-) for the increase in gas and s-glucose with different cut-off levels (normal values) and for the presence of any symptom-ELL.

\section{Discussion}

This study clearly demonstrates the unsatisfactory agreement between commonly used diagnostic tests for LM. The major methodological problem is the lack of a "gold

Table I: Characteristics of the patients with and without lactose malabsorption (LM).

\begin{tabular}{|c|c|c|c|}
\hline Patients' characteristics & LM & Not LM & Statistics \\
\hline Number of subjects & 7 & 53 & \\
\hline Male & $1 / 7(14 \%)$ & $16 / 53(30 \%)$ & $n s(p=0.66)$ \\
\hline Age in years & $46(35-55)$ & $36(|8-7|)$ & ns $(p=0.15)$ \\
\hline Scandinavian origin & $7 / 7(100 \%)$ & $52 / 53(98 \%)$ & ns $(p=1.00)$ \\
\hline Body Mass Index (BMI) & $21.1(20.1-27.3)$ & $24.8(18.5-37.2)$ & $p=0.027$ \\
\hline Organic bowel disease & $0 / 7(0 \%)$ & $4 / 53(8 \%)$ & $\mathrm{ns}(\mathrm{p}=1.00)$ \\
\hline Abdominal discomfort after intake of milk/dairy products & $4 / 6(67 \%)$ & $43 / 51$ (84\%) & $n s(p=0.28)$ \\
\hline Daily smoker & $1 / 7(14 \%)$ & $17 / 53(32 \%)$ & $n s(p=0.66)$ \\
\hline
\end{tabular}

The results are given as number of patients (percentage in brackets) or median (range in brackets). 
Table 2: Symptoms after intake of lactose in patients with and without lactose malabsorption (LM).

\begin{tabular}{lccc}
\hline Symptoms & $\begin{array}{c}\text { LM } \\
(\mathbf{N}=\mathbf{7})\end{array}$ & $\begin{array}{c}\text { Not LM } \\
(\mathbf{N}=\mathbf{5 2})\end{array}$ & Statistics \\
\hline Pain/discomfort all & $5 / 7(71 \%)$ & $21 / 52(40 \%)$ & $\mathrm{P}=0.223$ \\
Pain/discomfort-ELL & $5 / 7(71 \%)$ & $8 / 52(15 \%)$ & $\mathrm{P}=0.004$ \\
Borborygmi all & $5 / 7(71 \%)$ & $25 / 52(48 \%)$ & $\mathrm{ns}(\mathrm{P}=0.424)$ \\
Borborygmi-ELL & $5 / 7(71 \%)$ & $8 / 51(16 \%)$ & $\mathrm{P}=0.005$ \\
Bloating all & $5 / 7(71 \%)$ & $24 / 52(46 \%)$ & $\mathrm{ns}(\mathrm{P}=0.254)$ \\
Bloating-ELL & $5 / 7(71 \%)$ & $8 / 51(16 \%)$ & $\mathrm{P}=0.005$ \\
Diarrhoea all & $4 / 7(57 \%)$ & $16 / 52(31 \%)$ & $\mathrm{ns}(\mathrm{P}=0.213)$ \\
Diarrhoea-ELL & $3 / 7(43 \%)$ & $4 / 51(8 \%)$ & $\mathrm{P}=0.032$ \\
Constipation all & $0 / 7(0 \%)$ & $4 / 52(8 \%)$ & $\mathrm{ns}(\mathrm{P}=1.00)$ \\
Constipation-ELL & $0 / 7(0 \%)$ & $4 / 52(8 \%)$ & $\mathrm{ns}(\mathrm{p}=1.00)$ \\
Any symptom & $6 / 7(86 \%)$ & $32 / 52(62 \%)$ & $\mathrm{ns}(\mathrm{P}=0.40)$ \\
Any symptom-ELL & $6 / 7(86 \%)$ & $11 / 51(22 \%)$ & $\mathrm{P}=0.002$
\end{tabular}

ELL (= "Early and Long Lasting"): Symptoms starting within $5 \mathrm{~h}$ after intake of lactose and lasting for more than $2 \mathrm{~h}$. Any symptom-ELL = Any "Early and Long Lasting" symptom.

The results are given as number of patients with proportions in brackets.

standard" for the diagnosis of LM. Jejunal biopsies for assessment of lactase activity is an unreliable method due to the irregular dissemination of lactase in the intestine, the available genetic test does not detect all genetic disorders related to LM and does not diagnose secondary LM, breaths tests are highly dependent on the microflora throughout the gut, and serum glucose depends on the glucose absorption and metabolism [15]. Therefore this study assesses primarily the agreement between the test variables. But because assessment of agreement between tests requires a positive or negative result of the test, we had to diagnose LM in each patient. The final diagnosis of LM was based on an overall evaluation of all tests performed in each subject. This is the only applicable method when no formal "gold standard" is available. When the diagnosis was established, the best cut-off levels (normal values) for each of the continuous variables were chosen. A high sensitivity was preferred to avoid false negative results at the expense of a lower specificity.

Lactose breath test with measurement of $\mathrm{H} 2+\mathrm{CH} 4 \times 2$ was judged as the best test. It was superior to $\mathrm{H} 2+\mathrm{CH} 4$ because of better sensitivity and a somewhat higher area under the ROC-curve (tables 3 and 5). The sensitivity and specificity was $100 \%$ with cut-off levels (normal values) $<18 \mathrm{ppm}$ and $<53 \mathrm{ppm}$ respectively. Results in the range from 18 $\mathrm{ppm}$ to $52 \mathrm{ppm}$ render further tests necessary to obtain a conclusive diagnosis. The agreement between $\mathrm{H} 2+\mathrm{CH} 4$ and $\mathrm{H} 2+\mathrm{CH} 4 \times 2$ was, as expected, very good because most subjects with LM predominantly produce $\mathrm{H} 2$, and the variables are slight modifications of each other. Nevertheless, $\mathrm{H} 2+\mathrm{CH} 4 \times 2$ seem to be preferable in clinical use and have satisfactory diagnostic properties.

Breath tests with measurement of only $\mathrm{H} 2$ have been judged as reliable tests for $\operatorname{LM}[16,17]$. The recently published Rome Consensus Conference report states that measurement of breath $\mathrm{CH} 4$ excretion is not currently recommended to improve the diagnostic accuracy of the $\mathrm{H} 2$ breath test due to lack of evidence, and that further studies on other gases (mainly $\mathrm{CH} 4$ ) than $\mathrm{H} 2$ should be encouraged [15]. In this study, the agreement between $\mathrm{H} 2$ and any combination of $\mathrm{H} 2$ and $\mathrm{CH} 4$ was very good, but the lower sensitivity of $\mathrm{H} 2$ only made it inferior to the combination of $\mathrm{H} 2+\mathrm{CH} 4 \times 2$. Since about $30 \%$ of the adult population is so-called $\mathrm{CH} 4$-producers and the methanogenesis consumes large quantities of $\mathrm{H} 2$ to produce $\mathrm{CH} 4$, it is reasonable to measure $\mathrm{CH} 4$ in addition to $\mathrm{H} 2$. This study showed that measurement of $\mathrm{CH} 4$ in addition to $\mathrm{H} 2$ increased the diagnostic accuracy of the breath test and that $\mathrm{H} 2+\mathrm{CH} 4 \times 2$ was the best one despite the fact that the concentration of $\mathrm{CH} 4$ is variable both in fasting conditions and after meals [18].

S-glucose is an alternative to breath test. The agreement with the breath test was modest and clinically unsatisfactory, but the diagnostic properties (sensitivity, specificity, PPV, NPV, and LR) were identical with that of H2 (table $5)$. The poor agreement and identical diagnostic properties are the result of different diagnostic classification into health and disease of the two methods. Since no gold standard is at hand it is impossible to judge between them, but because of the low specificity of s-glucose and lower area under the ROC-curve we conclude in accordance with other publications that it is inferior to breath test with measurement of $\mathrm{H} 2$ or $\mathrm{H} 2+\mathrm{CH} 4 \times 2$ (tables 3 and 5) $[17,19]$.

Table 3: The results of the receiver operating characteristics curve (ROC) analyses for the test variables.

\begin{tabular}{lccc}
\hline Test variables & Area under ROC-curve & 95\% Cl & Statistics \\
\hline $\mathrm{H} 2+\mathrm{CH} 4 \times 2$ & 0.976 & $0.945-1.007$ & $\mathrm{P}<0.001$ \\
$\mathrm{H} 2+\mathrm{CH} 4$ & 0.969 & $0.931-1.007$ & $\mathrm{P}<0.001$ \\
$\mathrm{~s}-$ glucose & 0.924 & $0.836-1.013$ & $\mathrm{P}<0.001$ \\
$\mathrm{H} 2$ & 0.872 & $0.688-1.055$ & $\mathrm{P}<0.001$ \\
$\mathrm{CH} 4$ & 0.638 & $0.424-0.851$ & $\mathrm{~ns}(\mathrm{P}=0.185)$
\end{tabular}


Table 4: Agreement between the test variables with the best cut-off values.

\begin{tabular}{|c|c|c|c|c|}
\hline Variables & $\mathrm{H} 2+\mathrm{CH} 4 \times 2<18 \mathrm{ppm}$ & $\mathrm{H} 2+\mathrm{CH} 4<17 \mathrm{ppm}$ & $\mathrm{H} 2<16 \mathrm{ppm}$ & s-glucose $>0.9 \mathrm{mmol} / \mathrm{L}$ \\
\hline $\mathrm{H} 2+\mathrm{CH} 4<\mathrm{I} 7 \mathrm{ppm}$ & $0.91(p<0.001)$ & ----- & ---- & ----- \\
\hline $\mathrm{H} 2<16$ ppm & $0.81(p<0.001)$ & $0.90(p<0.001)$ & ---- & ---- \\
\hline $\mathrm{s}$-glucose $>0.9 \mathrm{mmol} / \mathrm{L}$ & $0.44(p=0.001)$ & $0.50(p<0.001)$ & $0.46(p=0.001)$ & ---- \\
\hline Any symptom-ELL & $0.38(p=0.002)$ & $0.43(p<0.001)$ & $0.41(p<0.001)$ & $0.25(p=0.032)$ \\
\hline
\end{tabular}

The results are given as kappa values with statistics ( $\mathrm{p}$-values) in brackets.

Registration of symptoms after intake of lactose has been used as a simple test for LM [14]. Evaluation of the onset, severity and duration of symptoms for 8 hours has been recommended [15]. This study shows in accordance with previous reports, that symptoms in general are highly unreliable and unfit for clinical use [2]. Symptoms questionnaires and symptom based criteria such as "Early and Long Lasting (ELL)-symptoms" have better diagnostic properties $[2,16]$. In this study ELL-symptoms were superior to unspecified symptoms after intake of lactose. These findings are in agreement with the Rome Consensus Conference that symptoms should be evaluated during and for some hours after the test, and that onset and duration are of importance [15]. But even ELL-symptoms showed unacceptable diagnostic properties and poor agreement with any of the other test (table 4 and 5). This fits with the clinical observation that the prevalence of perceived lactose intolerance, which is also related to visceral hypersensitivity, is significantly higher than that of LM, and that subjects with LM can consume a variable but limited amount of lactose without developing symptoms $[9,11,20]$.

In this study the genetic test was performed in only ten subjects with discrepancies at the first combined test and the results therefore give limited information about the usability of the test. The test is probably highly indicative of lactase non-persistence in adults $[12,13]$. But the fact that LM might be due to other genetic abnormalities and organic disorders in the gastrointestinal tract limits the clinical utility of the test $[21,22]$.
The selection criteria were pragmatic and based on perceived milk intolerance or symptoms judged as possible LM by the doctor. The selection was not strictly scientific, but according to everyday practice. The prevalence of LM was rather low despite the fact that most patients had symptoms related to intake of milk or lactose and were referred with suspected LM. This is in accordance with other studies in Scandinavia showing a low prevalence of LM both in the general population and in patients with FGID $[2,3]$. A somewhat lower BMI was the only clinical characteristic of subjects with LM, and has also been reported in other trials [23].

Performance of the breath tests varies. In this study, the tests were performed according to recently published guidelines concerning devices for breath sampling, stationary and immediate analyses, prolonged expiration and correction for alveolar $\mathrm{CO} 2$, use of antibiotics, diet, cigarette smoking and physical exercise [15]. However, no mouth washing was performed, and colonic clearing was not sufficiently taken into account, but was never performed in close relation to the test. A three-sample $\mathrm{H} 2$ breath test is favourable compared to a two-sample [24]. The five-sample test used in this trial strengthens the results. The length of the test was three hours; 4 hours have been recommended because some subjects have a slow transit [15]. In all, it is unlikely that these minor deviations from the recently published recommendations have had any significant influence on the results. Also the dose of lactose varies. Twenty-five gram lactose (equivalent to $500 \mathrm{~mL}$ milk), the dose used in this trial, seems reasonable and is the recommended dose [15]. This amount

Table 5: The diagnostic properties (sensitivity, specificity, positive and negative predictive values, accuracy and likelihood ratios (LR)) for the variables in the study with different cut-off levels (normal values).

\begin{tabular}{|c|c|c|c|c|c|c|c|c|}
\hline Variable & Normal value & Sensitivity & Specificity & PPV & NPV & Accuracy & LR + & LR- \\
\hline $\mathrm{H} 2+\mathrm{CH} 4 \times 2$ & $<53$ ppm & $44.4 \%$ & $100 \%$ & $100 \%$ & $92.4 \%$ & $92.9 \%$ & Inde-finite & 0.56 \\
\hline $\mathrm{H} 2+\mathrm{CH} 4 \times 2$ & $<18$ ppm & $100 \%$ & $90.2 \%$ & $60 \%$ & $100 \%$ & $91.4 \%$ & 10.2 & 0 \\
\hline $\mathrm{H} 2+\mathrm{CH} 4$ & $<17$ ppm & $88.9 \%$ & $91.8 \%$ & $61.5 \%$ & $98.2 \%$ & $91.4 \%$ & 10.8 & 0.12 \\
\hline $\mathrm{H} 2$ & <16 ppm & $77.8 \%$ & $93.4 \%$ & $63.6 \%$ & $96.6 \%$ & $91.4 \%$ & 11.9 & 0.24 \\
\hline s-glucose-increase & $>0.9 \mathrm{mmol} / \mathrm{L}$ & $77.8 \%$ & $93.4 \%$ & $63.6 \%$ & $96.6 \%$ & $91.4 \%$ & 11.9 & 0.24 \\
\hline Any symptom-ELL & Absent & $85.7 \%$ & $78.4 \%$ & $35.3 \%$ & $97.6 \%$ & $79.3 \%$ & 4.0 & 0.18 \\
\hline
\end{tabular}

The results are based on all performed tests. 
gives symptoms in most subjects with $\mathrm{LM}$ and is within the range of normal consumption $[9,11,25]$.

Practical and correct dietary advice to patients with FGID and food intolerance is impossible without valid and reliable tests for food intolerance. Such tests are by and large missing. Patients with food intolerance often make unnecessary changes in the diet which for some result in malnutrition $[6,26]$. Further improvement of the diagnostic armamentarium for food intolerance is desired to improve dietary treatment.

\section{Conclusion}

This trial shows unsatisfactory agreement between commonly used diagnostic tests for LM. The test with the best diagnostic properties was lactose breath test with $25 \mathrm{~g}$ lactose and measurement of the increase in the sum of $\mathrm{H} 2$ and $\mathrm{CH} 4 \times 2$. The area under the ROC-curve was 0.976 , sensitivity was $100 \%$ with a cut-off level $<18 \mathrm{ppm}$, and specificity was $100 \%$ with a cut-off level $<53$ ppm. Results in the range from $18 \mathrm{ppm}$ to $52 \mathrm{ppm}$ render further tests necessary to obtain a conclusive diagnosis.

\section{Competing interests}

The authors declare that they have no competing interests.

\section{Authors' contributions}

$\varnothing \mathrm{H}$ participated in the design of the study, took part in the acquisition of data, did most of the analyses and interpretation of the data and wrote the draft manuscript.

PGF was the main contributor to the concept and design of the study, took part in the acquisition of data, was responsible for analyses and interpretation of the data, and has written the final manuscript.

Both authors approved the published version.

\section{Acknowledgements}

We express our thanks to Innlandet Hospital Health Trust for financial support and to Registered Nurse Hilde Grønli for conscientious performance of the combined breath and s-glucose tests.

\section{References}

I. Vesa TH, Marteau P, Korpela R: Lactose intolerance. J Am Coll Nutr 2000, 19:165S-175S.

2. Farup PG, Monsbakken KW, Vandvik PO: Lactose malabsorption in a population with irritable bowel syndrome: Prevalence and symptoms. A case-control study. Scand J Gastroenterol 2004, 39:645-649.

3. Almon R, Engfeldt P, Tysk C, Sjöström M, Nilsson TK: Prevalence and trends in adult-type hypolactasia in different age cohorts in Central Sweden diagnosed by genotyping for the adulttype hypolactasia-linked LCT-I39 IOC $>$ T mutation. Scand J Gastroenterol 2007, 42:165-170.

4. Vesa TH, Seppo LM, Marteau PR, Sahi T, Korpela R: Role of irritable bowel syndrome in subjective lactose intolerance. Am J Clin Nutr 1998, 67:710-715.
5. Simrén M, Månsson A, Langkilde AM, Svedlund J, Abrahamsson H, Bengtsson $U$, et al: Food-related gastrointestinal symptoms in the irritable bowel syndrome. Digestion 200I, 63(2): I08-I I 5.

6. Monsbakken KW, Vandvik PO, Farup PG: Perceived food intolerance in subjects with irritable bowel syndrome - etiology, prevalence and consequences. Eur J Clin Nutr 2006, 60:667-672.

7. Vernia P, Di Camillo M, Marinaro V: Lactose malabsorption, irritable bowel syndrome and self-reported milk intolerance. Dig Liver Dis 200I, 33:234-239.

8. Lomer MC, Parkes GC, Sanderson JD: Review article: lactose intolerance in clinical practice - myths and realities. Aliment Pharmacol Ther 2008, 27:93-103.

9. Johnson AO, Semenya JG, Buchowski MS, Enwonwu CO, Scrimshaw NS: Adaptation of lactose maldigesters to continued milk intakes. Am J Clin Nutr 1993, 58:879-88।.

10. Hertzler SR, Huynn BC, Savaiano DA: How much lactose is low lactose? J Am Diet Assoc 1996, 96:243-246.

II. Hertzler SR, Savaiano DA: Colonic adaptation to daily lactose feeding in lactose maldigesters reduces lactose intolerance. Am J Clin Nutr 1996, 64:232-236.

12. Järvelä IE: Molecular genetics of adult-type hypolactasia. Ann Med 2005, 37: 179-185.

13. Högenauer C, Hammer HF, Mellitzer K, Renner W, Krejs G], Toplak $\mathrm{H}$ : Evaluation of a new DNA test compared with the lactose hydrogen breath test for the diagnosis of lactase non-persistence. Eur J Gastroenterol Hepatol 2005, 17:37I-376.

14. Beyerlein L, Pohl D, Delco F, Stutz B, Fried M, Tutuian R: Correlation between symptoms developed after the oral ingestion of $50 \mathrm{~g}$ lactose and results of hydrogen breath testing for lactose intolerance. Aliment Pharmacol Ther 2008, 27:659-665.

15. Gasbarrini A, Corazza GR, Gasbarrini G, Montalto M, Di Stefano M, Basilisco G, et al:: Methodology and indications of H2-breath testing in gastrointestinal diseases: the Rome Consensus Conference. Aliment Pharmacol Ther 2009, 29(suppl I): I-49.

16. Casellas F, Varela E, Aparici A, Casaus M, Rodríguez P: Development, validation, and applicability of a symptoms questionnaire for lactose malabsorption screening. Dig Dis Sci 2009, 54:1059-1065.

17. Newcomer AD, McGill DB, Thomas PJ, Hofman AF: Prospective comparison of indirect methods for detecting lactose deficiency. N Engl J Med 1975, 293: I232-I 235.

18. Corazza G, Strocchi A, Sorge M, Bentai G, Gasbarrini G: Prevalence and consistency of low breath $\mathrm{H} 2$ excretion following lactulose ingestion. Possible implications for the clinical use of the H2 breath test. Dig Dis Sci 1993, 38:2010-2016.

19. Hermans MM, Brummer RJ, Ruijgers AM, Stockbrügger RW: The relationship between lactose tolerance test results and symptoms of lactose intolerance. Am J Gastroenterol 1997, 92(6): $981-984$.

20. Di Stefano M, Miceli E, Mazzocchi S, Tana P, Moroni F, Corazza GR: Visceral hypersensitivity and intolerance symptoms in lactose malabsorption. Neurogastroenterol Motil 2007, 19:887-895.

21. Tishkoff SA, Reed FA, Ranciaro A, Voight BF, Babbitt CC, Silverman $\mathrm{JS}$, et al.: Convergent adaption of human lactase persistence in Africa and Europe. Nat Genet 2007, 39:3 I-40.

22. Bodé S, Gudmand-Høyer E: Incidence and clinical significance of lactose malabsorption in adult coeliac disease. Scand J Gastroenterol 1988, 23:484-488.

23. Landau DA, Goldberg A, Levi Z, Levi Y, Niv Y, Bar-Dayan Y: The prevalence of gastrointestinal diseases in Israeli adolescents and its association with body mass index, gender, and Jewish ethnicity. J Clin Gastroenterol. 2008, 42(8):903-909.

24. Di Camillo M, Marinaro V, Argnani F, Foglietta T, Vernia P: Hydrogen breath test for diagnosis of lactose malabsorption: The importance of timing and the number of breath samples. Can J Gastroenterol 2006, 20:265-268.

25. Bozzani A, Penagini R, Velio P, Camboni G, Corbellini A, Quatrini M, et al: Lactose malabsorption and intolerance in Italians. Dig Dis Sci 2005, 3 I ( ( 2): 1 $313-1316$.

26. Kull M, Kallikorm R, Lember M: Impact of molecularly defined hypolactasia, self-perceived milk intolerance and milk consumption on bone mineral density in a population sample in Northern Europe. Scand J Gastroenterol 2009, 44:4I 5-42I. 


\section{Pre-publication history}

The pre-publication history for this paper can be accessed here:

http://www.biomedcentral.com/1471-230X/9/82/pre

pub

Publish with Bio Med Central and every scientist can read your work free of charge

"BioMed Central will be the most significant development for disseminating the results of biomedical research in our lifetime. " Sir Paul Nurse, Cancer Research UK

Your research papers will be:

- available free of charge to the entire biomedical community

- peer reviewed and published immediately upon acceptance

- cited in PubMed and archived on PubMed Central

- yours - you keep the copyright 